\title{
The Role of Rotavirus in Exacerbated Ulcerative Colitis
}

\author{
Rawaa Ali ${ }^{1}$, Ghanim Aboud Jaber A-Mola ${ }^{2}$ \\ ${ }^{1}$ M.Sc. Student, ${ }^{2}$ Prof. Dr., University of Babylon, College of Science for Women, Department of Biology
}

\begin{abstract}
The Ulcerative colitis disease course is characterized by exacerbations and remissions. Studies of the role of viral composition within patients with changing disease activity are currently deficient. The rotavirus gastroenteritis is an important cause of morbidity and mortality worldwide. This study aimed to identify the associated role of Rotavirus during exacerbation of ulcerative colitis. A Fifteen (50) stool and biopsy samples from patients with exacerbated colitis were collected at different age groups and gender. These samples were taken from Morjan Hospital Consultant Gastroenterology and Liver Center, and the lmam Sadiq Hospital during the period from October to April 2019. The stool samples were screened for Rotavirus by using Rapid CERtest Rotavirus Kit,PCR The occurrences of UC and age revealed that the age group $<25$ year show ten with UC $83 \%$ followed by the age group (26-35) which give seven with UC $70 \%$. The relation between existence of UC and gender shown that the positive among male were (20) of patients UC $71 \%$ while negative (8) among female the positive were 17 (77\%)the results statistically non- significant. The frequency of rotavirus positivity during exacerbated UC as tested by Rapid CER test at different age group the results gives (23) positive samples for Rotavirus $46 \%$ and negative (27) $54 \%$. The Rotavirus existence in stool of patients with positive biopsy for ulcerative colitis by using chromatography test revealed that the number of positive were 20 out of 50 at a rate of $40 \%$. While the RT-PCR product analysis of VP4 gene in Rotavirus from in RNA extracted from stool patients samplesthe positive were 24 out of 50 with rate of $48 \%$.
\end{abstract}

Keywords: Ulcerative colitis, Exacerbation, Rotavirus, Cer-test, PCR.

\section{Introduction}

The Ulcerative colitis disease course is characterized by exacerbations and remissions. It is generally considered to arise from the interaction between host genetics, environmental factors, dysregulated immune responses and alterations in the intestinal microbiota composition. There are causative factors associated with the development of exacerbations. Many evidence suggests that gut microbe play a critical role in disease pathogenesis ${ }^{1}$ while geographic ${ }^{2}$ dietary and ethnic factors impact themicrobial composition. Most microbiota studies in UC have investigated the bacterial microbiota and alterations in fecal bacteria and fecal virome have been reported in patients with IBD. Patients with UC showed an expansion of Caudovirales bacteriophages and Caudovirales species richness in the stool. The gut microbial homeostasis between mucosa bacteria and viruses should be explored. Evidence of the prescence of some viruses like Epstein-Barr virus, HSV, Norovirus and CMV infections in the mucosal inflammatory cells of ulcerative colitis patients suggests a possible role of these virus in the causation of inflammatory bowel disease (IBD). However, ${ }^{3}$ unclear. Limited studies have) any role for CMV in exacerbation of inflammatory bowel disease (IBD) remains examined the microbiota composition in ulcerative colitis patients developing an exacerbation. However ${ }^{4}$ the importance of rotavirus, as an exacerbating factor of UC, has been neglected by many clinicians. Therefore, the aim of the present study was to explore the role of rotavirus in UC patients during exacerbation. ${ }^{5}$ In the study of ${ }^{6}$ On intestinal tissue, CMV genome was detected in $32.9 \%$ of patients with IBD and only in $2.4 \%$ of the controls; also a significant association was detected between CMV intestinal infection and either UC or $\mathrm{CD}$, although the association was even stronger for patients with UC. ${ }^{7}$

\section{Method}

The current study was conducted in Marjan Teching Hospital Gastroentrology and liver Unite and Imam 
Sadiq Hospital from October to April 2019 in which demographic, biopsy and feces samples were collected at outpatient visit and during an exacerbation. The diagnosis of UC was based on clinical and endoscopic examination by specialist physician. Fecal samples were collected at before endoscopy in each visit and stored at $4^{\circ} \mathrm{C}$. Part was examined by Rapid Cer test for viral detection and the remaining part was stored for analyses by PCR. Exclusion criteria were pregnancy, use of rectal enemas, use of antibiotics. The study was approved by the Medical Ethics Committee of Iraqi $\mathrm{MOH}$, and verbal consent was obtained from all subjects.

\section{Results}

Distribution of patients with UC during study period according to age. The association between occurrence of UC and age revealed that the age group $<25$ year show ten with UC $83 \%$ followed by the age group (26-35) which give seven with UC 70\% .Other age group (36-45) UC were seven $77 \%$ and (46-55) were six $75 \%$ also the group (56-66) show four with UC 66\% and the last age group show that (6) with UC\% 66 (table-1).

Table 1: Age distribution of patients with UC during study period

\begin{tabular}{|c|c|c|c|c|c|c|}
\hline Age & No. & With UC & $\mathbf{\%}$ & Without UC & \% & $\mathbf{X}^{\mathbf{2}} \mathbf{0 . 0 5}$ \\
\hline $1-25$ year & 12 & 10 & 83.33 & 2 & 16.66 & 3.32 \\
\hline $26-35$ & 10 & 7 & 70.00 & 3 & 22.00 & 1.6 \\
\hline $36-45$ & 9 & 7 & 77.77 & 22.76 & 2 \\
\hline $46-55$ & 8 & 6 & 75.00 & 2 & 33.33 & 0.66 \\
\hline $56-66$ & 6 & 4 & 66.66 & 2 & 40.00 & 0.2 \\
\hline$<67$ & 5 & 3 & 60.00 & 2 & $100 \%$ & \\
\hline
\end{tabular}

Distribution of Ulcerative Colitis according to gender. The results of relation between occurance of UC and gender shown that the positive among male (20) of patients UC $71 \%$ while negative (8) among female the positive were 17 (77\%) and the negative (5) (table 2).

Table 2: Distribution of cases of ulcerative colitis according to gender.

\begin{tabular}{|c|c|c|c|c|c|c|}
\hline \multirow{2}{*}{ Sex } & \multirow{2}{*}{ No. } & \multicolumn{3}{|c|}{ No. of Patients UC } & \multirow{2}{*}{$\%$} & \multirow{2}{*}{$X^{2} 0.05$} \\
\hline & & $+v e$ & $\%$ & -ve & & \\
\hline Male & 28 & 20 & 71.42 & 8 & 28.57 & 5.14 \\
\hline Female & 22 & 17 & 77.27 & 5 & 22.72 & 6.54 \\
\hline Total & 50 & 37 & $100 \%$ & 13 & $100 \%$ & \\
\hline
\end{tabular}

Frequency of Rotavirus positivity in patients during exacerbation of ulcerative colitis according to age. The frequency of rotavirus positivity during exacerbated UC as tested by Rapid CER test at different age group the results gives (7)positive samples for Rotavirus $46 \%$ and negative( 8 ) $53 \%$ at the age group (1-25). The other group (26-35) show (6) positive $60 \%$ and the negative (4) $40 \%$. A two positive $33 \%$ and four negative $66 \%$ in the group (36-45) followed by four positive $44 \%$ and five negative $55 \%$ at the (46-55) then positive $(3) 60 \%$ and negative(2) $40 \%$ at (56-65) the last age group $>66$ show one positive $20 \%$ and negative(4) $80 \%$ 
Table 3: The distribution of Rotavirus positivity in patients with exacerbation ulcerative colitis in relation to age of patients.

\begin{tabular}{|c|c|c|c|c|c|c|}
\hline \multirow{2}{*}{ Age Group } & \multirow{2}{*}{$\begin{array}{c}\text { No. of Tested } \\
\text { Patients }\end{array}$} & \multicolumn{2}{|c|}{ No. of Positive } & \multicolumn{2}{|c|}{ No. of Negative } & \multirow{2}{*}{$\mathbf{X}^{\mathbf{2}} \mathbf{0 . 0 5}$} \\
\cline { 3 - 7 } & 15 & No & $\mathbf{\%}$ & No & 53.33 & 0.06 \\
\hline $1-25$ & 10 & 6 & 46.66 & 8 & 40.00 & 0.04 \\
\hline $26-35$ & 6 & 2 & 33.33 & 4 & 66.66 & 0.66 \\
\hline $36-45$ & 9 & 4 & 44.44 & 5 & 55.55 & 0.55 \\
\hline $46-55$ & 5 & 3 & 60.00 & 2 & 40.00 & 0.2 \\
\hline $56-65$ & 5 & 1 & 20.00 & 4 & 80.00 & 1.8 \\
\hline$<67$ & $\mathbf{5 0}$ & $\mathbf{2 3}$ & $\mathbf{1 0 0} \%$ & $\mathbf{2 7}$ & $\mathbf{1 0 0 \%}$ & \\
\hline Total & & & & & \\
\hline
\end{tabular}

Rotavirus existence in stool of patients with positive biopsy for ulcerative colitis by using chromatography test. The existence of rotavirus in the stool samples of patient as examined by Rapid Certest according gender revealed that the Biopsy positive for UC were $12(40 \%)$ male while female was eight $(40 \%)$. The rotavirus positive after endoscopic gives (13)\% 43 positive male while female have seven positive $35 \%$. (table- 4 ).

Table 4: The Rotavirus existence in stool of patients with positive biopsy for ulcerative colitis by using chromatography test.

\begin{tabular}{|c|c|c|c|c|c|c|c|c|c|c|c|}
\hline \multicolumn{2}{|c|}{$\begin{array}{l}\text { No of Patients } \\
\text { Examine }\end{array}$} & \multicolumn{4}{|c|}{ Biopsy Positive for UC } & \multicolumn{4}{|c|}{$\begin{array}{c}\text { Stool Examination Rota Positive after } \\
\text { Endoscopic }\end{array}$} & \multirow{2}{*}{$\begin{array}{l}X^{2} 0.05 \\
\text { Biopsy }\end{array}$} & \multirow{2}{*}{$\begin{array}{l}X^{2} 0.05 \\
\text { Stool }\end{array}$} \\
\hline Sex & NO & $+\mathrm{ve}$ & $\%$ & -ve & $\%$ & $+\mathrm{ve}$ & $\%$ & -ve & $\%$ & & \\
\hline Male & 30 & 12 & 40.00 & 18 & 60.00 & 13 & 43.33 & 17 & 56.66 & 1.2 & 0.52 \\
\hline Female & 20 & 8 & 40.00 & 12 & 60.00 & 7 & 35.00 & 13 & 65.00 & 0.8 & 1.8 \\
\hline Total & 50 & 20 & $100 \%$ & 30 & $100 \%$ & 20 & $100 \%$ & 30 & $100 \%$ & & \\
\hline
\end{tabular}

PCR test for Rotavirus of examined patients with Biopsy positive and stool positive. The molecular method used PCR results display that the biopsy positive (10) at $38.46 \%$ for male gender while in the stool examined positive after endoscopic(14) at $58.33 \%$ for female.

Table 5: The Rotavirus existence in stool sample of patients with positive biopsy for ulcerative colitis tested by PCR.

\begin{tabular}{|c|c|c|c|c|c|c|c|c|c|c|c|}
\hline \multicolumn{2}{|c|}{$\begin{array}{l}\text { No of Patients } \\
\text { Examined }\end{array}$} & \multicolumn{4}{|c|}{ Biopsy Positive } & \multicolumn{4}{|c|}{ Stool Examined Positive after Endoscopic } & \multirow{2}{*}{$\begin{array}{l}X^{2} 0.05 \\
\text { Biopsy }\end{array}$} & \multirow{2}{*}{$\begin{array}{c}X^{2} 0.05 \\
\text { Stool }\end{array}$} \\
\hline Sex & NO & +ve & $\%$ & -ve & $\%$ & $+v e$ & $\%$ & -ve & $\%$ & & \\
\hline Male & 26 & 10 & 38.46 & 16 & 61.53 & 15 & 57.69 & 11 & 42.30 & 1.38 & 0.6 \\
\hline Female & 24 & 14 & 58.33 & 10 & 41.66 & 11 & 45.83 & 13 & 54.16 & 0.66 & 0.166 \\
\hline Total & 50 & 24 & $100 \%$ & 26 & $100 \%$ & 26 & $100 \%$ & 24 & $100 \%$ & & \\
\hline
\end{tabular}

RT-PCR results of stool samples from exacerbated ulcerative colitis 


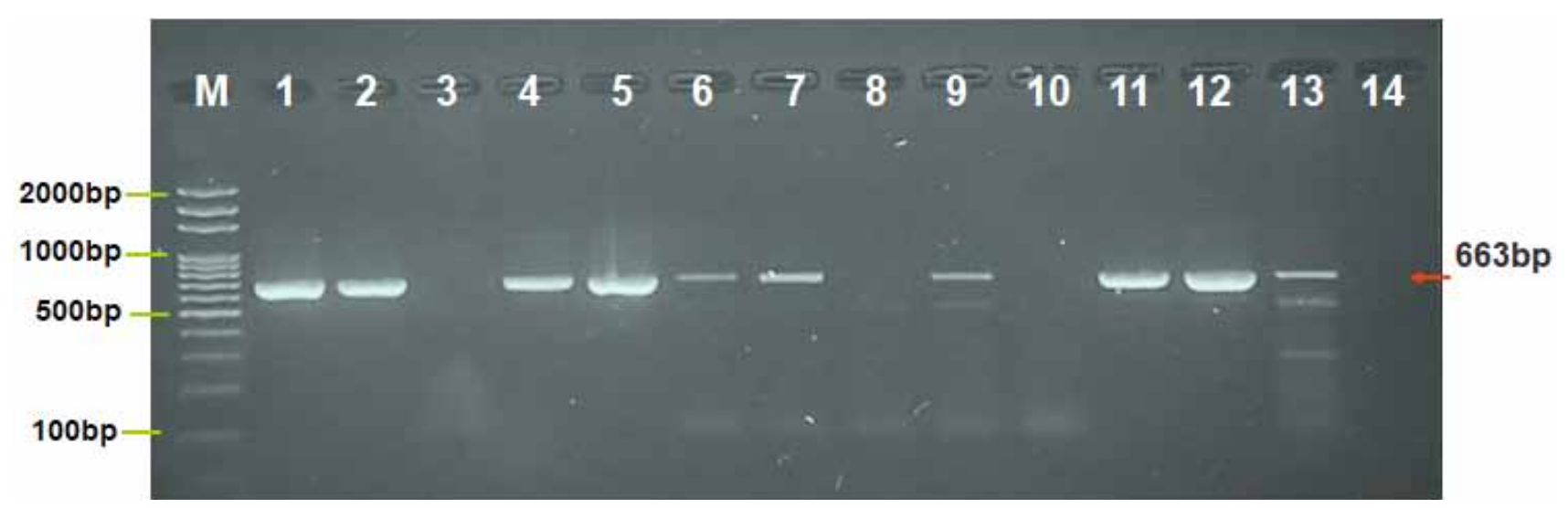

Figure 1: RT-PCR for the samples from exacerbated Ulcerative colitis.

Agarose gel electrophoresis image that showed the RT-PCR product analysis of VP4 gene in Rotavirus from in RNA extracted from stool patients samples, where ladder (2000-100bp), lane (1-14) some samples with positive VP4 gene in Rotavirus at (663bp) PCR product size.

\section{Discussion}

Although the pathogenesis of inflammatory bowel disease remains unclear, several studies have suggested that the onset and development of inflammatory bowel disease require the interaction between genetic susceptibility,stimulation by luminal bacterial antigens and adjuvants, and episodic environmental triggers which break the mucosal barrier.In therapy-refractory and fulminant cases of ulcerative colitis infectious causes have to be kept in mind. Numerous viral and bacterial agents have been associated with complicated or therapy-refractory course of ulcerative colitis especially in immunocompromised patients. Most of these viruses are bacteriophages, including those found in the gut, and insert genes into the bacterial DNA. The close relationship between gut bacteriophages and bacteria raises the possibility that there could also be a relationship between these resident viruses and UC, although this connection is only beginning to be explored. ${ }^{8}$.Viruses Complicating Ulcerative colitis Several viruses with a facultative intestinal organotropy such as cytomegalovirushuman parvovirus B19,Epstein-Barr virus and herpes simplex virus have been reported. However, the absolute numbers have not been investigated thoroughly, comparative analyses are lacking so far. ${ }^{1}$ The presence of norovirus in stool and/or rectal swab samples, as determined by an enzyme-linked immunoassay, was assessed. In addition, sex, age, type of IBD, presence or absence of diarrhea, hematochezia, and the need for hospitalization were determined. The Khan etal.(2009) concluded that norovirus may be associated with exacerbations of IBD. The results of this study consistent with the observation of ${ }^{9}$ that up to $40 \%$ of the exacerbations were associated with symptoms of antecedent or concurrent infection, most commonly involving the respiratory tract. Rubella virus, EpsteinBarr virus, and adenovirus were associated with acute exacerbations. Till our knowledge no data available about the association of rotavirus with ulcerative colitis. The rotavirus may be associated with exacerbations and play a role in complicating ulcerative colitis.

Financial Disclosure: There is no financial disclosure.

Conflict of Interest: None to declare.

Ethical Clearance: All experimental protocols were approved under the College of Science for Women and all experiments were carried out in accordance with approved guidelines.

\section{References}

1. Eckburg PB, Bik EM, Bernstein CN, Purdom E, Dethlefsen L, et al. Diversity of the human intestinal microbial flora. Science 2005;308: 1635-1638.

2. Sokol H, Seksik P, Rigottier-Gois L, Lay C, Lepage $\mathrm{P}$, et al. Specificities of the fecal microbiota in inflammatory bowel disease. Inflamm Bowel Dis 2006;12: 106-111.

3. Cadwell K. The virome in host health and disease. Immunity 2015;42:805-13. 
4. Virgin HW. The virome in mammalian physiology and disease. Cell 2014;157:142-50.

5. Kishore J, Ghoshal U, Ghoshal UC, Krishnani N, Kumar S, Singh M, et al. Infection with cytomegalovirus in patients with inflammatory bowel disease: prevalence, clinical significance and outcome. J Med Microbiol. 2004; 53 :1155 -60

6. Dimitroulia A. Dimitroulia E, Pitiriga VC, Piperaki ET, Spanakis NE, Tsakris A. Inflammatory bowel disease exacerbation associated with Epstein-Barr virus infection. Dis Colon Rectum. 2013; 56(3) : $322-7$

7. Hommes A. Hommes DW, Sterringa G, van
Deventer SJ, Tytgat GN, Weel J. The pathogenicity of cytomegalovirus in inflammatory bowel disease: a systematic review and evidence-based recommendations for future research. Inflamm Bowel Dis. 2004; 10(3) : 245 -50

8. Sokol H, Seksik P, Furet JP, Firmesse O, NionLarmurier I. Low counts of Faecalibacterium prausnitzii in colitis microbiota. Inflamm Bowel Dis 2009; 15: 1183-1189.

9. Kangro HO, Chong SK, Hardiman A, Heath RB, Walker-Smith JA.: A prospective study of viral and mycoplasma infections in chronic inflammatory bowel disease. Gastroenterology . 1990; 98 (3): 549-53. 